\title{
COMPLICATIONS DURING A SUPRACLA- VICULAR ANESTHESIA OF THE BRACHIAL PLEXUS WITH INTERSCALENE APPROACH
}

\author{
Minko Minkov ${ }^{1}$, Maria Vankova ${ }^{1}$, Radoslav Minkov ${ }^{2}$, Stefaniya Terzieva ${ }^{1}$, Toni \\ Dimitrov $^{3}$, Iskren Velikov ${ }^{1}$ \\ 1) Department of Anatomy, Histology and Embryology, Medical University - Varna \\ 2) SBAGAL "Prof. d-r D. Stamatov" - Varna, Bulgaria \\ 3) MBAL "Saint Anna" Hospital - Varna, Bulgaria
}

\section{SUMMARY}

A hemidiaphragmatic paresis is one of the most frequently observed complications following the supraclavicular anesthesia of the brachial plexus with interscalene approach. In patients, crucially dependant on adequate diaphragmatic function, hemidiaphragmatic paresis may provoke acute respiratory disturbances.

The aim of this study was to analyze the anatomical features the brachial plexus with regard of the anesthesia of specific areas of the shoulder and the upper limb.

A dissection of the cervical and the brachial plexuses was done in human cadavers. We established that in some cases the phrenic nerve and the accessory phrenic nerve arise from the superior trunk of the brachial plexus. This type of anatomical arrangement significantly increases the risk of hemidiaphragmatic paresis during supraclavicular anesthesia with interscalene approach because the anesthetic tends to invade the supraclavicular space.

Key words: phrenic nerve, accessory phrenic nerve, brachial plexus, cervical plexus.

\section{INTRODUCTION}

The supraclavicular anesthesia of the brachial plexus ensures a quick start and a full block of all branches of the plexus. The most frequent complications during a supraclavicular anesthesia of the brachial plexus with interscalene approach are the vascular incidents and the hemidiaphragmatic paresis. In patients, crucially dependant on adequate function of the diaphragm, the hemidiaphragmatic paresis may provoke acute respiratory disturbances $(4,5,6,7)$.

The aim of this study is to research the anatomical features of the brachial plexus with regard of the anesthesia of the upper limb and clarify the reasons for the occurrence of complications.

\section{MATERIAL AND METHODS}

Twelve cadavers of adult individuals from the cadaver's fund of the Department of Anatomy, Histology and Embryology of the Medical University - Varna were dissected and studied.

The anatomy of the brachial plexus and the dissected blood vessels in the cervical regions and the superior mediastinum were colored with nitrocellulose paints and were documented using a Minolta camera.

\section{RESULTS AND DISCUSSION}

The general arrangement of the brachial plexus was confirmed by our study. It is formed by the anterior rami of the cervical spinal nerves $\mathrm{C}_{5}, \mathrm{C}_{6}, \mathrm{C}_{7}, \mathrm{C}_{8}$ and most of the anterior ramus of the first thoracic spinal nerve $\mathrm{Th}_{1}$. The branches of the cervical spinal nerves pass laterally, going between $\mathrm{mm}$. intertransversarii anteriores cervicis and $\mathrm{mm}$. intertransversarii posteriores cervicis and enter the space between the anterior scalene muscle and the middle scalene muscle, spatium interscalenum. The subclavian artery lies in the inferior part of this space, just above the first rib. Above and behind the subclavian artery are the trunks of the brachial plexus. Within the spatium interscalenum the subclavian artery gives rise to the costocervical trunk. The trunks of the brachial plexus pass through the lateral cervical region, giving rise to a number of nerves for the shoulder girdle and enter the axillary fossa. In the lateral cervical region the brachial plexus is covered by the lamina prevertebralis of the cervical fascia; medially to the inferior belly of the omohyoid muscle it is also covered by the lamina pretrachealis of the cervical fascia. 
The phrenic nerve is known to be a major branch of the cervical plexus. The fourth cervical spinal nerve takes part in its formation and in some cases it receives fibers from the third and fifth cervical spinal nerves. It is the major motor nerve of the cervical plexus and contains motor, viscerosensory and sympathetic fibers $(1,2,3)$. The phrenic nerve gives rise to branches for the pleura, pericardium, peritoneum, liver, gall bladder and adrenal gland $(1,2,3)$.

Our data shows that in 23 cases the nerve is situated on the anterior surface of the anterior scalene muscle, laterally to the ascending cervical artery and the thyrocervical trunk, between the subclavian vein and subclavian artery and enters the superior mediastinum. In the middle mediastinum it passes between the mediastinal pleura and the pericardium, anterior to the hilum of the lung, enters the corresponding half of the diaphragm and innervates it.

According to Kadanov (1964) in $60 \%$ of the cases an accessory phrenic nerve exists. It passes laterally to the phrenic nerve, anterior to the subclavian vein and at the level of the first rib connects with the phrenic nerve. According to Vankov and Ovcharoff (2010) the accessory phrenic nerve begins as a separate branch or in a common trunk with the phrenic nerve, passes laterally to it and innervates the diaphragm.

During our study we came across a peculiar variation of the phrenic nerves. In one cadaver we found that the right phrenic nerve and the right accessory phrenic nerve, arise as branches of the superior trunk of the brachial plexus (fig. 1). The phrenic nerve passes behind the suprascapular artery, between the subclavian artery and subclavian vein and enters the superior mediastinum. Here the nerve passes between the right brachiocephalic vein and the internal thoracic artery and connects with the accessory phrenic nerve in the area of the union of the brachiocephalic veins (fig. 2). In a case like this application of supraclavicular anesthesia with interscalene approach and the spread of the local anesthetic in the supraclavicular space would significantly increase the risk of hemidiaphragmatic paresis. We also suggest that lamina prevertebralis and lamina pretrachealis of the cervical fascia, which cover the brachial plexus contribute to the spread of the local anesthetic in medial direction, towards the phrenic nerve.

\section{CONCLUSION}

Our results show that in certain cases the phrenic nerve is more vulnerable during application of supraclavicular anesthesia with interscalene approach, due to its anatomical variation.. Therefore we believe that despite the advantages of this type of anesthesia the application of infraclavicular anesthesia is safer and will significantly lower the risk of hemidiaphragmatic paresis. 


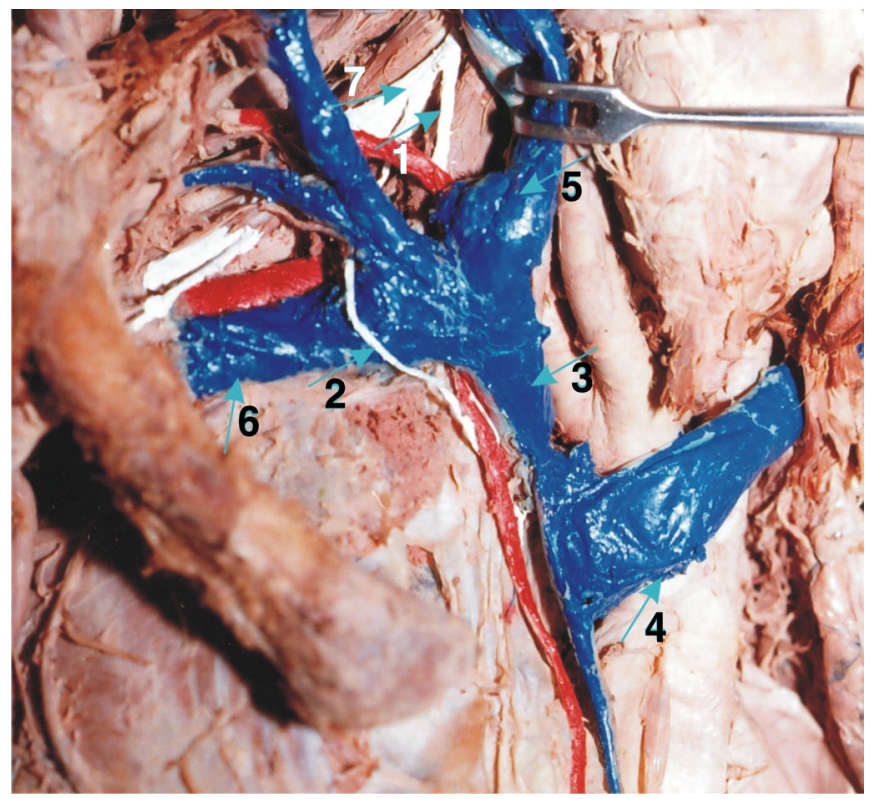

Fig.1. 1) phrenic nerve, 2) accessory phrenic nerve, 3) right brachiocephalic vein, 4) left brachiocephalic vein, 5) internal jugular vein, 6) subclavian vein, 7) brachial plexus.

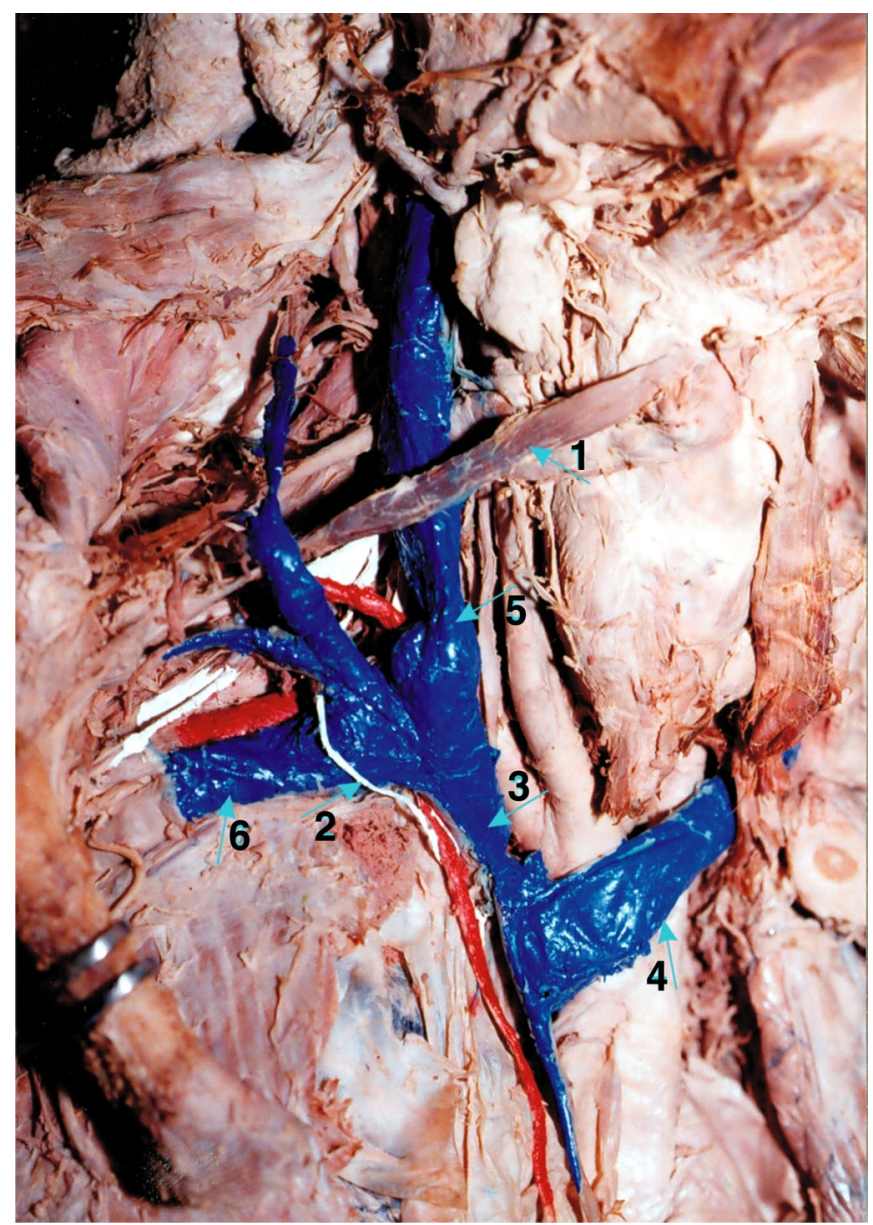

Fig. 2. 1) omohyoid muscle, 2) accessory phrenic nerve, 3) right brachiocephalic vein, 4) left brachiocephalic vein, 5) internal jugular vein, 6) subclavian vein.

\section{REFERENCES:}

1. Vankov V, Ovcharoff V. Human anatomy, Medicinsko izdatelstvo “ARSO”, Sofia, 2010, 11 izdanie: 831. (in Bulgarian)

2. Kadanov D, Balan M, Stanishev D., Human anatomy, Medicina $i$ fizkultura, Sofia, 1964: 519-531. (in Bulgarian)

3. Williams PL, Warwick R, Dyson M, Barnister LH. GRAY'S ANATOMY (37th edition), Edinburgh etc., Churchill Livingstone, 1989: 11281130.

4. Karadimov D, Vassilev D, Kostadinova R, Sabov R. Local regional anesthesia in the ambulatory surgery, Astra Zeneca, Sofia, 2003: 7094. (in Bulgarian)

5. Thompson GE, Rorie DK.
Functional anatomy of the brachial plexus sheaths. Anesthesiology, 1983; Aug;59(2):117-122. [PubMed]

6. Winnie AP. Interscalene brachial plexus block. Anesth Analg., 1970; MayJun;49(3):455-466. [PubMed]

7. Albrecht H, Berle P etc. Regional anasthesie. Gustav Fisher Verlag, Stuttgart, New York, 1985: 5-47.

Address for correspondence:

Stefaniya Terzieva, MD, PhD

Department of Anatomy, Histology and Embryology, Medical University 55, "Marin Drinov" str., Varna, Bulgaria

E-mail: stefaniaterziewa@yahoo.com; 